\title{
Boron-doped $\mathrm{p}-\mathrm{BaSi}_{2} / \mathrm{n}$-Si solar cells formed on textured $\mathrm{n}$-Si(001) with a pyramid structure consisting of $\{111\}$ facets
}

Tianguo Deng ${ }^{\mathrm{a}}$, Kazuhiro Gotoh ${ }^{\mathrm{b}}$, Ryota Takabe ${ }^{\mathrm{a}}$, Zhihao Xua ${ }^{\mathrm{a}}$, Suguru Yachi ${ }^{\mathrm{a}}$, Yudai Yamashita ${ }^{\mathrm{a}}$, Kaoru Toko ${ }^{\mathrm{a}}$, Noritaka Usami ${ }^{\mathrm{b}}$, Takashi Suemasu ${ }^{\mathrm{a}^{*}}$

${ }^{a}$ Institute of Applied Physics, University of Tsukuba, Tsukuba, Ibaraki 305-8573, Japan

${ }^{\mathrm{b}}$ Graduate School of Engineering, Nagoya University, Furo-cho, Chikusa-ku, Nagoya 4648603, Japan

* Corresponding author.

Electronic mail: suemasu@bk.tsukuba.ac.jp 
$\mathrm{BaSi}_{2}$ films were fabricated on textured $\mathrm{Si}(001)$ substrates that consisted of $\{111\}$ facets using molecular beam epitaxy. The light-trapping effect of these films and their performance when incorporated into solar cells were measured. X-ray diffraction and reflectivity measurements showed that the $\mathrm{BaSi}_{2}$ films were grown epitaxially on the textured $\mathrm{Si}(001)$ substrate and confirmed the light-trapping effect. The critical thickness over which $\mathrm{BaSi}_{2}$ relaxes increased from approximately 50 to $100 \mathrm{~nm}$ when comparing the $\mathrm{BaSi} 2$ films on a flat $\mathrm{Si}(111)$ substrate and the textured substrate, respectively. $\mathrm{p}-\mathrm{BaSi}_{2} / \mathrm{n}-\mathrm{Si}$ solar cells were fabricated with varying $\mathrm{BaSi}_{2}$ layer thickness and with hole concentrations in the range between $2.0 \times 10^{18}$ and $4.6 \times$ $10^{18} \mathrm{~cm}^{-3}$. These cells exhibited a maximum energy conversion efficiency of $4.62 \%$ with an open-circuit voltage of $0.30 \mathrm{~V}$ and a short-circuit current density of $27.6 \mathrm{~mA} / \mathrm{cm}^{2}$ when the p$\mathrm{BaSi}_{2}$ layer was $75 \mathrm{~nm}$-thick. These results indicated that the use of $\mathrm{BaSi}_{2}$ films on textured $\mathrm{Si}(001)$ substrates in solar cells shows great promise.

Keywords: A3.MBE; B1.Semiconducting silicides; B2. BaSi2; B3.Solar cell 


\section{Introduction}

A significant amount of work on a wide variety of solar cell materials, including cadmium telluride, chalcopyrite, kesterite, and perovskite, has been performed to realize high energy conversion efficiencies $(\eta)$ in low-cost solar cells [1-4]. However, many of these materials contain rare and/or toxic elements. Thus, finding suitable absorber materials that are environment-friendly is of great importance. Semiconducting barium disilicide ( $\left.\mathrm{BaSi}_{2}\right)$ shows great promise as it has a suitable band gap (1.3 eV) [5-8], a large absorption coefficient $(\alpha)$ of $3 \times 10^{4} \mathrm{~cm}^{-1}$ at $1.5 \mathrm{eV}[6,9]$, which is comparable to chalcopyrite, and a large minority-carrier lifetime $(\tau)$ of approximately $10 \mu \mathrm{s}[10,11]$. This leads to a large minority-carrier diffusion length $(L)$ of approximately $10 \mu \mathrm{m}$, which is much larger than the grain size of $\mathrm{BaSi}_{2}$ [12]. An $\eta$ over $25 \%$ is expected for a $2 \mu$ m-thick $\mathrm{BaSi}_{2}$ pn junction solar cell [13]. We have previously grown boron (B)-doped $\mathrm{p}-\mathrm{BaSi}_{2}$ on a flat $\mathrm{n}-\mathrm{Si}(111)$ substrate to form pn junction solar cells and achieved an $\eta$ of $9.9 \%[14,15]$. $\mathrm{Si}(111)$ substrates were used with $\mathrm{BaSi}_{2}$ rather than $\mathrm{Si}(001)$ substrates because the oriented $a$-axis led to a significantly smaller lattice mismatch (approximately 1\%) [16], they have inactive grain boundaries [17, 18], and they have a much longer $L$ [19]. However, $\operatorname{Si}(001)$ substrates are far more abundant than $\operatorname{Si}(111)$ substrates. To attain these favorable features on $\operatorname{Si}(001)$ substrates, they can be textured with $\operatorname{Si}\{111\}$ facets by etching. These textured structures have been used to trap incident light, which improves solar cell performance [20-22], with reports of their use in thin-film silicon solar cells with a 
high short-circuit current density of $32.9 \mathrm{~mA} / \mathrm{cm}^{2}$ in a single-junction $\mu \mathrm{c}-\mathrm{Si}: \mathrm{H}$ cell [23].

We have investigated the solar cell performance of $\mathrm{p}-\mathrm{BaSi}_{2} / \mathrm{n}-\mathrm{Si}$ heterojunction solar cells. To ensure epitaxial growth of the $\mathrm{BaSi}_{2}$ film on a textured $\mathrm{Si}(001)$ substrate and examine the light-trapping effects and solar cell operation, we first grew undoped-BaSi2 films on the textured $\mathrm{Si}(001)$ substrate using molecular beam epitaxy (MBE).The morphologies and light trapping behavior of these samples were examined. We then fabricated B-doped $\mathrm{p}-\mathrm{BaSi} 2$ films on textured $\mathrm{n}-\mathrm{Si}(001)$ substrates to form $\mathrm{p}-\mathrm{BaSi}_{2} / \mathrm{n}-\mathrm{Si}$ solar cells with a $\mathrm{p}-\mathrm{BaSi}_{2}$ layer thicknesses $(d)$ from 20 to $125 \mathrm{~nm}$ and with hole concentrations $(p)$ from $2.0 \times 10^{18}$ to $4.6 \times$ $10^{18} \mathrm{~cm}^{-3}$. The performances of these cells were then examined. A maximum $\eta$ of $4.62 \%$ was achieved when the $\mathrm{p}-\mathrm{BaSi}_{2}$ layer thickness was $75 \mathrm{~nm}$ and the $p$ was $3.6 \times 10^{18} \mathrm{~cm}^{-3}$.

\section{Experimental}

An ion-pumped MBE (R-DEC) system with a base pressure less than $10^{-8} \mathrm{~Pa}$ was used in this study. This was equipped with an electron-beam evaporation source for Si and standard Knudsen cells for Ba and B. The samples were prepared as follows: first, the (001) surface of a Czochralski n-Si(001) substrate $(\rho=1-5 \Omega \mathrm{cm})$ was cleaned by acetone and methanol to eliminate organics followed by dipping in $\mathrm{HF} / \mathrm{HNO}_{3}$ mixed acid. Then, the substrate was immersed into SUN-X 600 (Wako) at $75{ }^{\circ} \mathrm{C}$ for $30 \mathrm{~min}$ to form a pyramid structure consisting of $\{111\}$ facets [24], and cleaned by sulfuric acid at $120^{\circ} \mathrm{C}$ for $15 \mathrm{~min}$. After thermal cleaning 
of the substrate, $\mathrm{Ba}$ was deposited at $500{ }^{\circ} \mathrm{C}$ to form a $5 \mathrm{~nm}$-thick $\mathrm{BaSi}_{2}$ epitaxial template by reactive deposition epitaxy. This template acted as a seed crystal for the growth of the subsequent layer. $\mathrm{Ba}$ and $\mathrm{Si}$ were co-deposited on the template at $580{ }^{\circ} \mathrm{C}$ using $\mathrm{MBE}$ to form a $\mathrm{BaSi}_{2}$ epitaxial film that was approximately $400 \mathrm{~nm}$-thick (sample A). The deposition rates of $\mathrm{Si}$ and $\mathrm{Ba}$ were controlled using an electron impact emission spectroscopy (EIES; INFICON) feedback system. For comparison, another $400 \mathrm{~nm}$-thick BaSi2 epitaxial film was prepared on a flat $\mathrm{Si}(111)$ substrate (sample B). The reflectance spectra of samples A and B were compared. $\mathrm{B}$-doped $\mathrm{p}-\mathrm{BaSi}_{2} / \mathrm{n}-\mathrm{Si}$ solar cells with $d$ values ranging from 20 to $125 \mathrm{~nm}$ were grown with different sets of B K-cell temperature $\left(T_{\mathrm{B}}\right)$ and substrate temperature $\left(T_{\mathrm{S}}\right)$. Temperature sets $\left(T_{\mathrm{B}}, T_{\mathrm{S}}\right)$ of $\left(1230{ }^{\circ} \mathrm{C}, 600{ }^{\circ} \mathrm{C}\right),\left(1230{ }^{\circ} \mathrm{C}, 650{ }^{\circ} \mathrm{C}\right)$, and $\left(1300{ }^{\circ} \mathrm{C}, 650{ }^{\circ} \mathrm{C}\right)$ were used for samples C, D, and E, respectively. Subsequently, a $3 \mathrm{~nm}$-thick amorphous Si capping layer was prepared at $T_{\mathrm{S}}=180{ }^{\circ} \mathrm{C}$ over the $\mathrm{BaSi}_{2}$ layers for all the samples to prevent oxidation of the $\mathrm{BaSi}_{2}$ layer. Pole-figure X-ray diffraction (XRD; RIGAKU, Smart Lab) measurements were performed ( $\mathrm{Cu} \mathrm{K \alpha}$ radiation) on sample A at $2 \theta=62.42^{\circ}$ to determine whether the $a$-axis was normal to the $\{111\}$ facets. The diffraction angle $2 \theta=62.42^{\circ}$ allowed for the detection of $\mathrm{X}$ ray diffraction caused by the $\mathrm{BaSi}_{2}(600)$ plane. We derived the $a$-axis lattice constant $(a)$ of the $\mathrm{BaSi}_{2}$ in sample $\mathrm{C}$ using the Nelson-Riely relationship [25] with the angle of the sample surface $\chi$ fixed at $54.7^{\circ}$ with respect to the horizontal plane. The angle $\chi=54.7^{\circ}$ corresponds to the angle between the $\mathrm{Si}(001)$ and (111) faces. Optical characterizations required sputtering $80 \mathrm{~nm}$ - 
thick indium-tin-oxide $($ ITO $)$ electrodes $($ diameter $=1 \mathrm{~mm})$ on the front surface and $150 \mathrm{~nm}$ thick $\mathrm{Al}$ on the back surface. The current density versus voltage $(J-V)$ characteristics under standard AM1.5 illumination and the photoresponse spectra were measured using a xenon lamp with a 25-cm focal-length single monochromator (Bunko Keiki, SM-1700A and RU-60N). The reflectance spectra were evaluated using an integrating sphere. Light intensity was calibrated using a pyroelectric sensor (Melles Griot 13PEM001/J). The morphology of the undoped-BaSi2 surface was observed using field-emission scanning electron microscopy (FE-SEM; HITACHI). Cross-sectional transmission electron microscopy (TEM; FEI, Tecnai Osiris) with an acceleration voltage of $200 \mathrm{kV}$ was used to examine cross sections of the $\mathrm{BaSi}_{2}$ layers on the textured substrate. Thin foils for TEM observation were prepared with an ion beam microsampling system. The carrier concentrations of samples C-E were analyzed at ambient temperature via Hall measurements using the van der Pauw method.

\section{Results and discussion}

SEM images of sample A before and after the growth of the $\mathrm{BaSi}_{2}$ films are shown in Figure 1. Four $\{111\}$ facets were observed in each pyramid (Fig. 1(b)), with each pyramid being approximately $7 \mu \mathrm{m}$. The faces of the $\mathrm{BaSi}_{2}$ were very smooth even after growing a $400 \mathrm{~nm}$ thick $\mathrm{BaSi}_{2}$ film (Fig. 1(c)). However, the four ridgelines of each pyramid and the boundaries between the pyramids were rough, which may have been caused by the coalescence of $\mathrm{BaSi}_{2}$ 
grains grown on adjacent $\operatorname{Si}\{111\}$ facets. The pole-figure XRD pattern of sample A using $\mathrm{BaSi}_{2}(600)$ diffraction $\left(2 \theta=62.42^{\circ}\right)$ is shown in Figure 2(a). Four diffraction peaks appeared at $\chi=54.7^{\circ}$ as indicated by the four dotted circles. This was confirmed by the $\varphi$-scan XRD pattern at $\chi=54.7^{\circ}$, shown in Figure. 2(b). Here, $\varphi$ is the angle of rotation around the normal. These results showed that the $a$-axis of the $\mathrm{BaSi}_{2}$ was oriented normal to the textured $\{111\}$ surfaces of the Si (001) substrate.

The reflection spectra of samples A and B are shown in Figure. 3. The reflectance of sample $\mathrm{A}\left(\mathrm{BaSi}_{2}\right.$ film on textured $\mathrm{Si}(001)$ substrate) was significantly lower than that of sample B ( $\mathrm{BaSi}_{2}$ film on flat $\mathrm{Si}(111)$ substrate) over a wide wavelength range, which indicated that light trapping was occurring. On the basis of these promising results, we fabricated and characterized a series of $\mathrm{p}-\mathrm{BaSi}_{2} / \mathrm{n}-\mathrm{Si}$ heterojunction solar cells.

We investigated the strain induced in the $\mathrm{p}-\mathrm{BaSi}_{2}$ layer when $d$ was varied in films prepared using the conditions used for sample C. The $\theta-2 \theta$ scan XRD spectra obtained at $\chi=$ $54.7^{\circ}$ are shown in Figure 4. Diffraction peaks caused by $\mathrm{BaSi}_{2}$ when $d$ was $20 \mathrm{~nm}$ were very weak. However, diffraction peaks of (100)-oriented BaSi2 planes, including (200), (400) and (600) planes, were observed when $d$ was $50 \mathrm{~nm}$ and above, which indicated the growth of highly $a$-axis-oriented $\mathrm{BaSi}_{2}$ epitaxial films. Using these three peaks in each sample, the $a$-axis lattice constants were calculated. The strain $(\Delta a / a)$ as a function of $\mathrm{BaSi}_{2}$ film thickness normalized using the sample with the largest $d$ is shown in Figure 5. For comparison, the values of $\Delta a / a$ for 
$\mathrm{BaSi}_{2}$ films on the flat substrate were plotted. As the value of $d$ increased from 50 to $100 \mathrm{~nm}, a$ decreased by approximately $0.3 \%$, followed by a slight decrease up to $d=400 \mathrm{~nm}$. This indicated that $\mathrm{BaSi}_{2}$ was under compressive strain along the $a$ axis when $d<100 \mathrm{~nm}$, and the critical thickness over which $\mathrm{BaSi}_{2}$ became relaxed was approximately $100 \mathrm{~nm}$. Interestingly, the critical thickness increased from approximately $50 \mathrm{~nm}$ for a $\mathrm{BaSi}_{2}$ film on the flat $\mathrm{Si}(111)$ substrate to approximately $100 \mathrm{~nm}$ for a $\mathrm{BaSi}_{2}$ film on the textured substrate. It is plausible that the elastic strain energy within the $\mathrm{BaSi}_{2}$ film on the textured substrate was smaller than that within the film on the flat substrate because the domain size of the $\mathrm{BaSi}_{2}$ was limited to the area of each $\{111\}$ facet. Further studies are required to gain a greater understanding of this phenomenon.

The surface morphology of a $50 \mathrm{~nm}$-thick B-doped $\mathrm{p}-\mathrm{BaSi}_{2}$ film on the textured $\mathrm{Si}(001)$ substrate, sample C, was observed using SEM at different magnifications (Fig. 6). The surfaces of $\mathrm{BaSi}_{2}$, both on the $\{111\}$ facets and on the ridgelines of the pyramids, were rough (Fig. 6(a)), while the magnified image (Fig. 6(b)) showed that $\mathrm{BaSi}_{2}$ had layered growth on the facets.

A bright-field (BF) cross-sectional TEM image of sample $\mathrm{C}$ with a $d$ value of $50 \mathrm{~nm}$ is shown in Figure 7(a). An electron diffraction (SAED) pattern obtained around the $\mathrm{BaSi} / \mathrm{Si}$ interface area, as indicated by the gray dash circle in Fig. 7(a), is shown in Figure 7(b). The

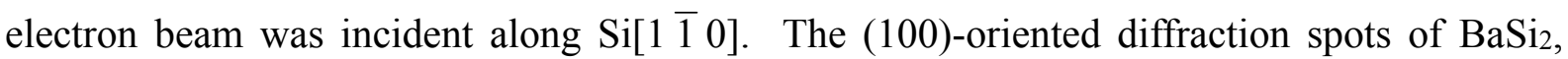
including (200), (400), and (600), were aligned with the (111)-oriented diffraction spots of Si, 
which indicated that the $a$-axis of the p-BaSi2 was grown epitaxially on the $\{111\}$ facet of the Si. A high-resolution TEM image near the $\mathrm{BaSi}_{2} / \mathrm{Si}$ interface showed that the $\mathrm{BaSi}_{2}$ film was oriented well and had formed uniformly on the Si substrate with a sharp interface (Fig. 7(c)). However, several steps were observed at the positions marked by the white arrows in Figure 7(d) with a step height in the Si facet of approximately $6 \mathrm{~nm}$. A magnified TEM image around this step is shown in Figure 7(e). Disordered lattices were observed, which may form defective centers for minority carriers. Improved etching techniques will be necessary to avoid these step structures.

$J-V$ curves (AM1.5 illumination) and internal quantum efficiency (IQE) spectra for samples $\mathrm{C}, \mathrm{D}$, and $\mathrm{E}$ with different values of $d$ are shown in Figures 8(a)-(f). Their values of $p$ were found to be $2.0 \times 10^{18}, 4.6 \times 10^{18}$, and $3.6 \times 10^{18} \mathrm{~cm}^{-3}$, respectively. The best properties for each solar cell are summarized in Table.1. $\mathrm{p}-\mathrm{BaSi}_{2}(20 \mathrm{~nm}) / \mathrm{n}-\mathrm{Si}$ solar cells that were fabricated on a flat $\mathrm{n}-\mathrm{Si}(111)$ substrate[14] with an $\eta$ of $9.9 \%$ are shown for comparison. To accurately obtain the reverse-bias saturation current density $\left(J_{0}\right)$, the shunt resistance $\left(R_{\mathrm{SH}}\right)$, the series resistance $\left(R_{\mathrm{s}}\right)$, and the ideality factor $(\gamma)$ of the diode, we adopted a technique described in the literature [26]. Using the photodiode equation, these parameters can be given as:

$$
\frac{d V}{d J}=S R_{\mathrm{S}}+\frac{\gamma k_{\mathrm{B}} T}{q}\left[\frac{1-\left(S R_{\mathrm{SH}}\right)^{-1} d V / d J}{J+J_{S C}-\left(S R_{\mathrm{SH}}\right)^{-1} V}\right] .
$$

where $S$ is the device area, $k_{\mathrm{B}}$ is the Boltzmann constant, $T$ is the absolute temperature, $q$ is the elemental charge, and $J_{\mathrm{SC}}$ is the short-circuit current density. We can see from Figures 8 (a) and 
(b) that as $d$ increased from 20 to $125 \mathrm{~nm}$, the solar cell performance initially improved and then degraded with a significant decrease in $J_{\mathrm{SC}}$ from 28.4 to $18.8 \mathrm{~mA} / \mathrm{cm}^{2}$. The value of $p$ was $2.0 \times 10^{18} \mathrm{~cm}^{-3}$ in sample C. Thus, the $J_{\mathrm{SC}}$ reached a maximum at $d=50 \mathrm{~nm}$ and then decreased. The IQE spectra shown in Figure 8(b) confirmed this.

The contribution of photogenerated carriers in the $\mathrm{p}-\mathrm{BaSi}_{2}$ layer became smaller as $d$ increased, especially in the short wavelength range. Similar results were observed for samples D (Fig. 8(d)) and E (Fig. 8(f)), which indicated that as $d$ increased, the photogenerated minority carriers (electrons) within the $\mathrm{p}-\mathrm{BaSi}_{2}$ layer were not able to efficiently reach the junction before recombination. Hence, a lower $p$ in the $\mathrm{p}-\mathrm{BaSi}_{2}$ layer increased the contribution of $\mathrm{p}-\mathrm{BaSi}_{2}$ to the photocurrent. The value of $p$ in sample D was $4.6 \times 10^{18} \mathrm{~cm}^{-3}$. As $d$ increased the $\eta$ increased to a maximum of $2.66 \%$ at $d=125 \mathrm{~nm}$ (Figs. 8(c) and (d)). The IQE spectrum of the $75 \mathrm{~nm}$ thick sample had the largest $I Q E$ over the whole wavelength range. Sample E $\left(p=3.6 \times 10^{18}\right.$ $\mathrm{cm}^{-3}$ ) exhibited a maximum $\eta$ of $4.62 \%$ at $d=75 \mathrm{~nm}$ (Figs. 8(e) and (f)). Although the reflectance for the $\mathrm{BaSi}_{2}$ film on the textured substrate was smaller (Fig. 3), the highest $J_{\mathrm{SC}}$ was limited to $28.5 \mathrm{~mA} / \mathrm{cm}^{2}$ in sample C. This value was significantly lower than that obtained for the $\mathrm{p}-\mathrm{BaSi}_{2} / \mathrm{n}-\mathrm{Si}$ solar cells fabricated on the flat $\mathrm{Si}(111)$ substrate $\left(35.2 \mathrm{~mA} / \mathrm{cm}^{2}\right)$ [14]. This result suggested that the minority-carrier diffusion length within the $\mathrm{p}-\mathrm{BaSi}_{2}$ and/or textured n$\mathrm{Si}(001)$ had degraded. Furthermore, the values of $V_{\mathrm{OC}}$ in samples $\mathrm{C}-\mathrm{E}$ were approximately half of those observed for the devices fabricated on the flat substrate, which indicating that the 
$\mathrm{BaSi}_{2} / \mathrm{Si}$ interfaces was defective. We speculate that $\mathrm{BaSi}_{2}$ grown around the ridge lines of each Si pyramid (Fig. 1(b)) and around the Si steps on the $\{111\}$ facets (Fig. 7(e)) might be the cause of the lower $J_{\mathrm{SC}}$ and $V_{\mathrm{OC}}$ parameters. Hence, improvements in $\eta$ are probable through optimization of the Si surface treatment and growth conditions of the $\mathrm{BaSi}_{2}$ layer.

\section{Conclusion}

We successfully fabricated $\mathrm{BaSi}_{2}$ films on textured $\mathrm{Si}(001)$ substrate with $\{111\}$ facets. Epitaxial growth of the $\mathrm{BaSi}_{2}$ films was confirmed using XRD and TEM. The critical thickness of the $\mathrm{BaSi}_{2}$ film was approximately $100 \mathrm{~nm}$, which is much larger than for $\mathrm{BaSi}_{2}$ films on a flat $\mathrm{Si}(111)$ substrate $(50 \mathrm{~nm})$. The reflectance of $\mathrm{BaSi}_{2}$ on the textured substrate was lower than that on the flat substrate, which indicated that light-trapping took place. $\mathrm{p}-\mathrm{BaSi}_{2} / \mathrm{n}-\mathrm{Si}$ solar cells with $d$ values between 20 and $125 \mathrm{~nm}$ and $p$ values between $2.0 \times 10^{18}$ and $4.6 \times 10^{18} \mathrm{~cm}^{-3}$ were fabricated. A maximum $\eta$ of $4.62 \%$ was observed at $d=75 \mathrm{~nm}$.

\section{Acknowledgements}

The authors thank Dr. N. Yoshizawa and Mr. N. Saito of the National Institute of Advanced Industrial Science and Technology for the TEM work. This work was financially supported by the Japan Science and Technology Agency (JST/CREST) and by a Grant-in-Aid for Scientific Research A (15H02237) from the Japan Society for the Promotion of Science (JSPS). R.T. was 
financially supported by a Grant-in-Aid for JSPS Fellows (15J02139). 


\section{Figure captions}

Fig. 1. SEM surface images of sample A. (a) Bird's-eye view of the substrate, (b) top-view of the substrate, and (c) $400 \mathrm{~nm}$-thick BaSi2 layer on top of the substrate.

Fig. 2. (a) Pole-figure XRD pattern of sample A using $\mathrm{BaSi}_{2}(600)$ diffraction with $2 \theta=62.42^{\circ}$.

(b) $\varphi$-Scan XRD pattern with $\chi=54.7^{\circ}$

Fig. 3. Reflectance spectra of sample A (400 nm-thick undoped-BaSi2 on the textured $\mathrm{Si}(001)$ substrate) and of sample B (400 nm-thick undoped $\mathrm{BaSi}_{2}$ on the flat $\mathrm{Si}(111)$ substrate).

Fig. 4. $\theta-2 \theta$ XRD spectra of B-doped p-BaSi2 films (sample C) with $d$ values from 20 to 400 $\mathrm{nm}$. The angle $\chi$ was set at $54.7^{\circ}$, which corresponds to the angle between the $\mathrm{Si}(001)$ and $\operatorname{Si}(111)$ planes.

Fig. 5. Normalized strain $(\Delta a / a)$ as a function of film thickness $(d)$ for the B-doped p-BaSi2 layers on the textured $\mathrm{Si}(001)$ and flat $\mathrm{Si}(111)$ substrates.

Fig. 6. SEM surface images of (a) $50 \mathrm{~nm}$-thick B-doped $\mathrm{p}-\mathrm{BaSi}_{2}$ on the textured substrate, sample $\mathrm{C}$, and (b) a magnified image of the area marked by the black dash circle in (a). 
Fig.7. (a) BF TEM cross sections of a $50 \mathrm{~nm}$-thick B-doped p-BaSi2 film near the top of the $\mathrm{Si}$ pyramid. (b) SAED pattern near the $\mathrm{p}-\mathrm{BaSi}_{2} / \mathrm{Si}$ interface area indicated by the gray dash circle in (a) (The electron beam was incident along $\operatorname{Si}[1 \overline{1} 0]$. The white dotted line is shown as a guide.) (c) High-resolution TEM image near the $\mathrm{p}-\mathrm{BaSi}_{2} / \mathrm{Si}$ interface. (d) BF TEM cross section of a step with a height of approximately $6 \mathrm{~nm}$, as indicated by white arrows. (e) High-resolution TEM image of the area marked by a white dash circle in (d).

Fig. 8. $J$ - $V$ curves under AM1.5 illumination and IQE spectra of sample C ((a) and (b)), sample D ((c) and (d)), and sample E ((e) and (f)). 


\section{References}

[1] M. Gloeckler, I. Sankin, Z. Zhao, IEEE Journal of Photovoltaics 3 (2013) 1389-1393.

[2] P. Reinhard, A. Chirilă, P. Blösch, F. Pianezzi, S. Nishiwaki, S. Buechelers, A.N. Tiwari, in: 2012 IEEE 38th Photovoltaic Specialists Conference (PVSC) PART 2, 2012, pp. 1-9.

[3] G. Niu, X. Guo, L. Wang, J. Mater. Chem. A 3 (2015) 8970-8980.

[4] M. A. Green, K. Emery, Y. Hishikawa, W. Warta, E.D. Dunlop, Progress in Photovoltaics: Research and Applications 24 (2016) 3-11.

[5] K. Morita, Y. Inomata, T. Suemasu, Thin Solid Films 508 (2006) 363-366.

[6] K. Toh, T. Saito, T. Suemasu, Japanese Journal of Applied Physics 50 (2011) 068001.

[7] M. Kumar, N. Umezawa, M. Imai, Applied Physics Express 7 (2014) 071203.

[8] T. Suemasu, N. Usami, Journal of Physics D: Applied Physics 50 (2017) 023001.

[9] D. B. Migas, V. L. Shaposhnikov, V. E. Borisenko, physica status solidi (b) 244 (2007) 2611-2618.

[10] K. O. Hara, N. Usami, K. Nakamura, R. Takabe, M. Baba, K. Toko, T. Suemasu, Applied Physics Express 6 (2013) 112302.

[11] K.O. Hara, N. Usami, K. Toh, M. Baba, K. Toko, T. Suemasu, Journal of Applied Physics 112 (2012) 083108.

[12] M. Baba, K. Toh, K. Toko, N. Saito, N. Yoshizawa, K. Jiptner, T. Sekiguchi, K.O. Hara, N. Usami, T. Suemasu, Journal of Crystal Growth 348 (2012) 75-79.

[13] T. Suemasu, Japanese Journal of Applied Physics 54 (2015) 07JA01.

[14] S. Yachi, R. Takabe, H. Takeuchi, K. Toko, T. Suemasu, Applied Physics Letters 109 (2016) 072103.

[15] D. Tsukahara, S. Yachi, H. Takeuchi, R. Takabe, W. Du, M. Baba, Y. Li, K. Toko, N. Usami, T. Suemasu, Applied Physics Letters 108 (2016) 152101.

[16] R. A. McKee, F. J. Walker, J. R. Conner, R. Raj, Applied Physics Letters 63 (1993) 2818-2820.

[17] M. Baba, S. Tsurekawa, K. Watanabe, W. Du, K. Toko, K.O. Hara, N. Usami, T. Sekiguchi, T. Suemasu, Applied Physics Letters 103 (2013) 142113.

[18] M. Baba, M. Kohyama, T. Suemasu, Journal of Applied Physics 120 (2016) 085311.

[19] M. Baba, K. Watanabe, K.O. Hara, K. Toko, T. Sekiguchi, N. Usami, T. Suemasu, Japanese Journal of Applied Physics 53 (2014) 078004.

[20] Y. Inomata, T. Nakamura, T. Suemasu, F. Hasegawa, Japanese Journal of Applied Physics 43 (2004) L478L481.

[21] M. Despeisse, G. Bugnon, A. Feltrin, M. Stueckelberger, P. Cuony, F. Meillaud, A. Billet, C. Ballif, Applied Physics Letters 96 (2010) 073507.

[22] F. J. Haug, K. Söderström, A. Naqavi, C. Ballif, Journal of Applied Physics, 109 (2011) 084516.

[23] H. Sai, T. Matsui, T. Koida, K. Matsubara, M. Kondo, S. Sugiyama, H. Katayama, Y. Takeuchi, I. Yoshida, Applied Physics Letters 106 (2015) 213902.

[24] T. Tayagaki, D. Furuta, O. Aonuma, I. Takahashi, Y. Hoshi, Y. Kurokawa, N. Usami, Japanese Journal of Applied Physics 56 (2017) 04CS01.

[25] J. B. Nelson, D. P. Riley, Proceedings of the Physical Society 57 (1945) 160. 
[26] J. R. Sites, P. H. Mauk, Solar Cells 27 (1989) 411-417. 
(a)

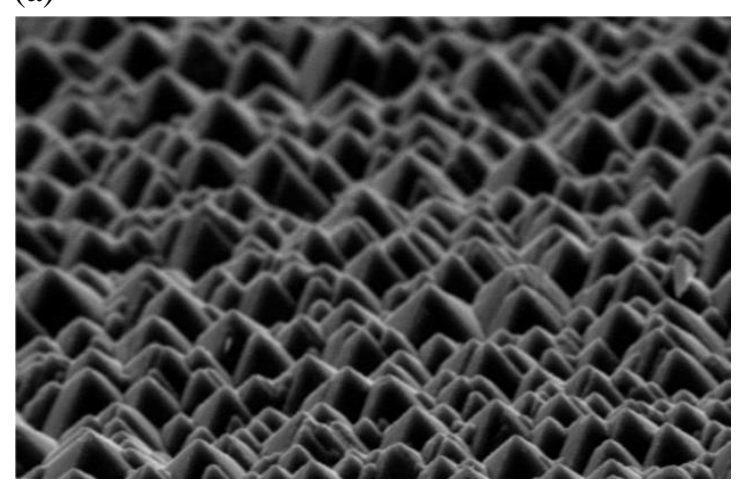

(b)
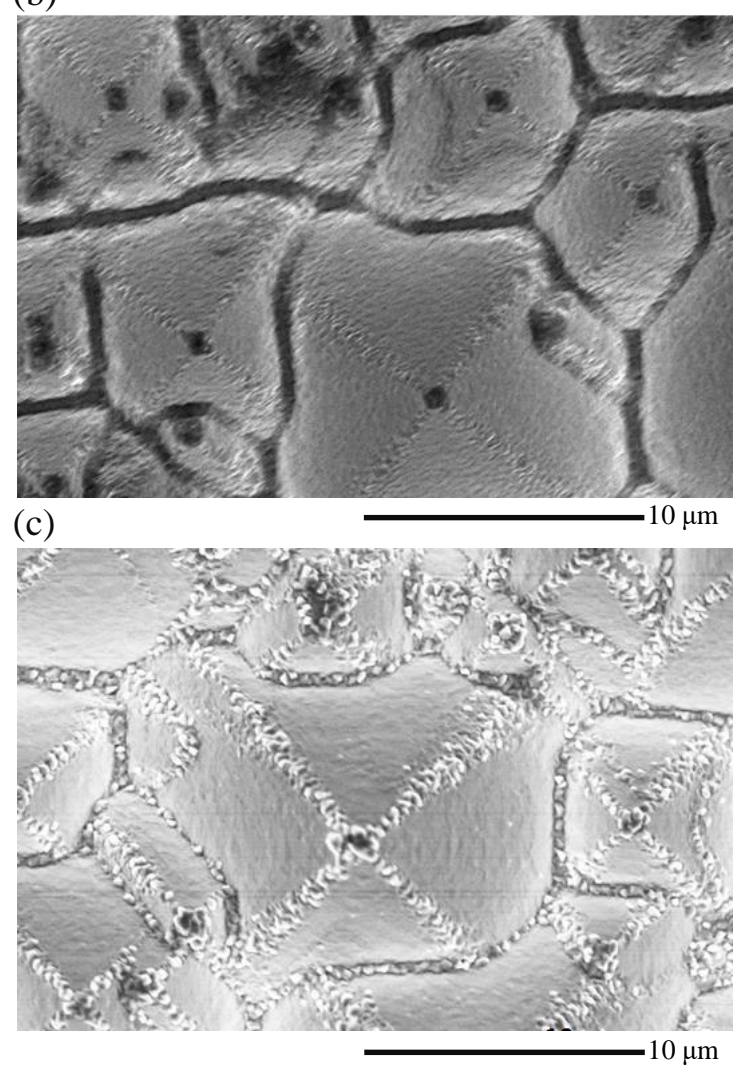

Fig. 1 

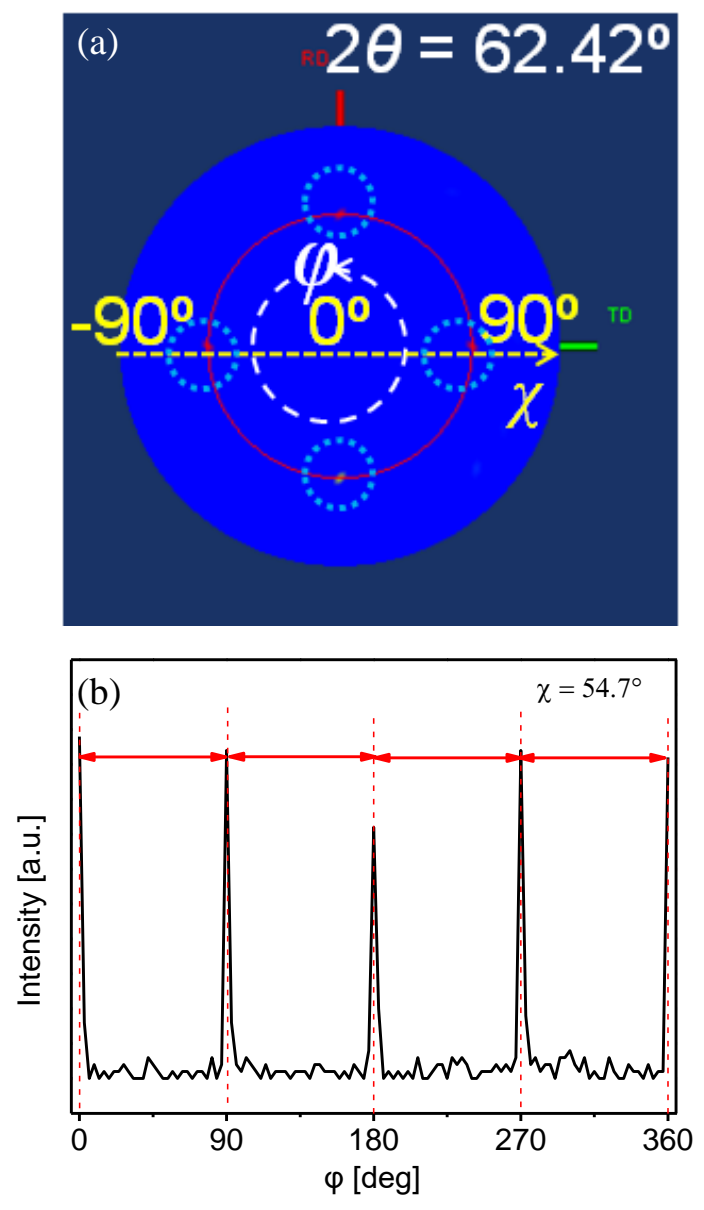

Fig. 2 


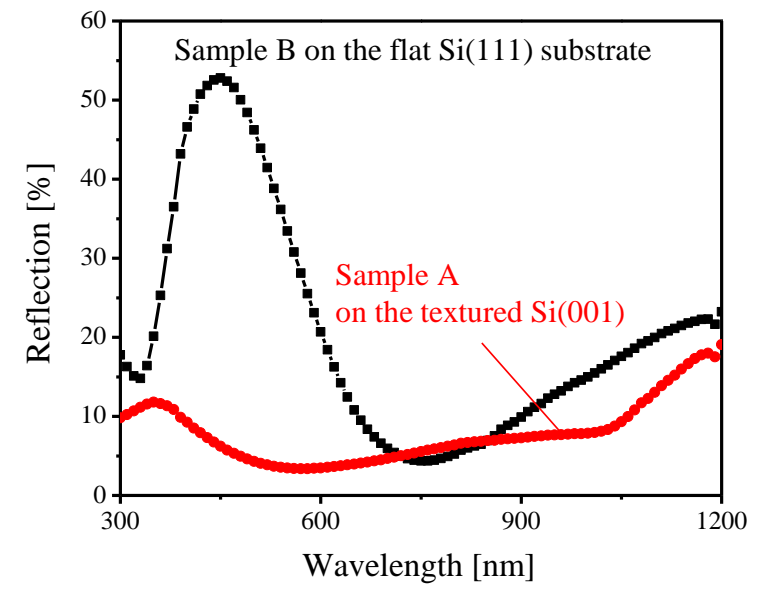

Fig. 3 


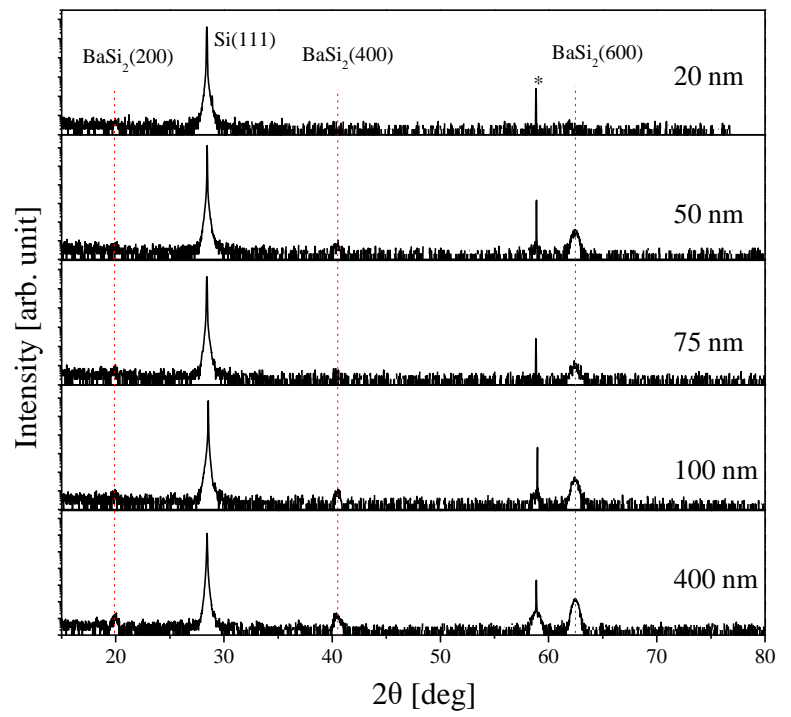

Fig. 4 


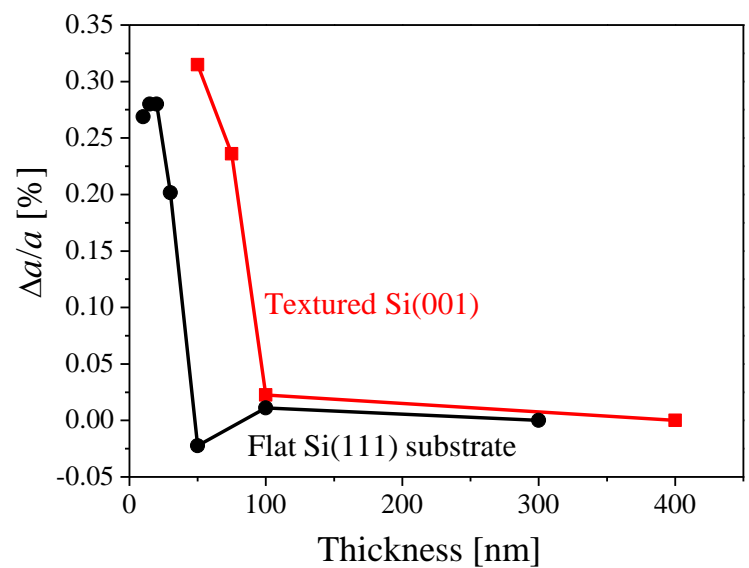

Fig. 5 
(a)

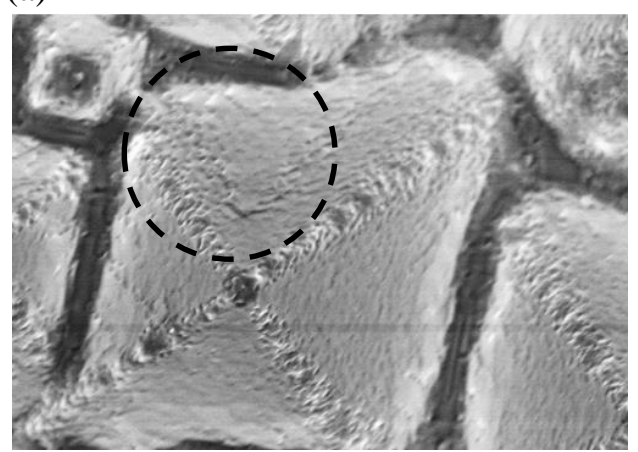

(b)

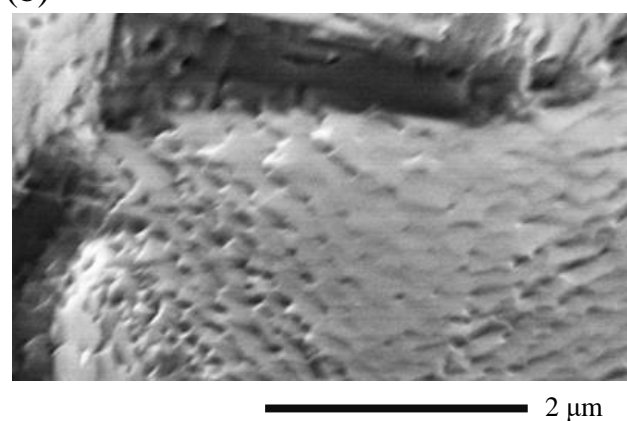

Fig. 6 
(a)

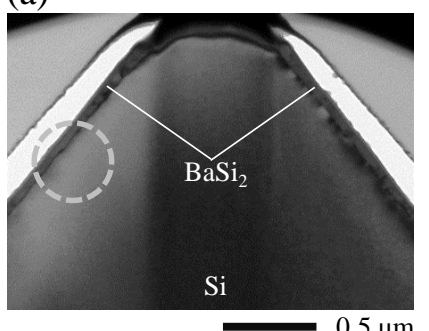

(c)

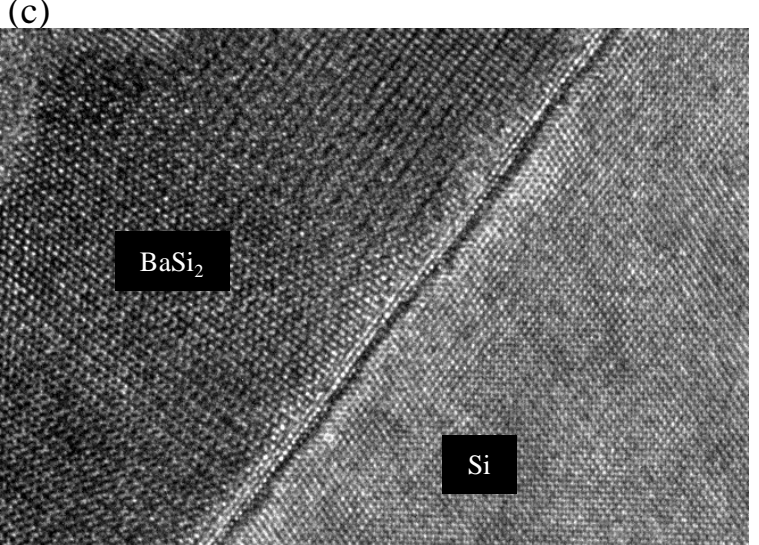

(d)

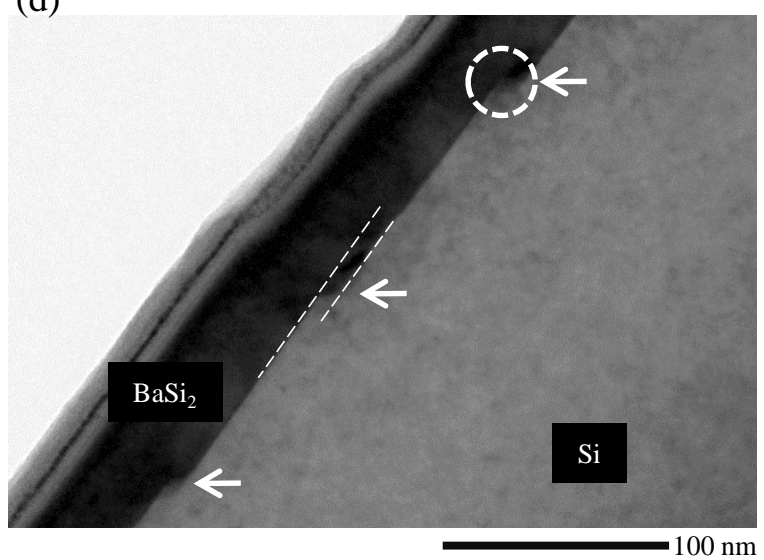

(e)

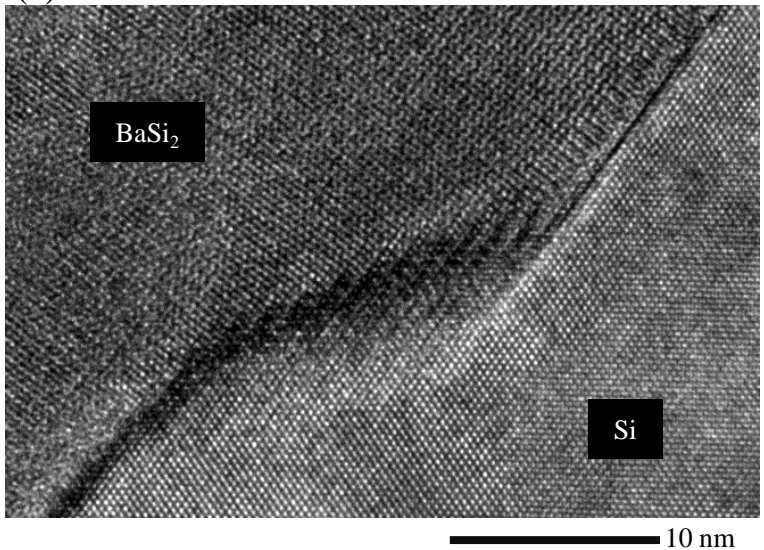

(b)

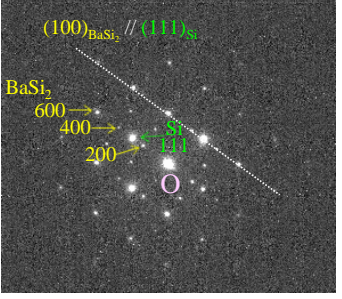

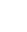



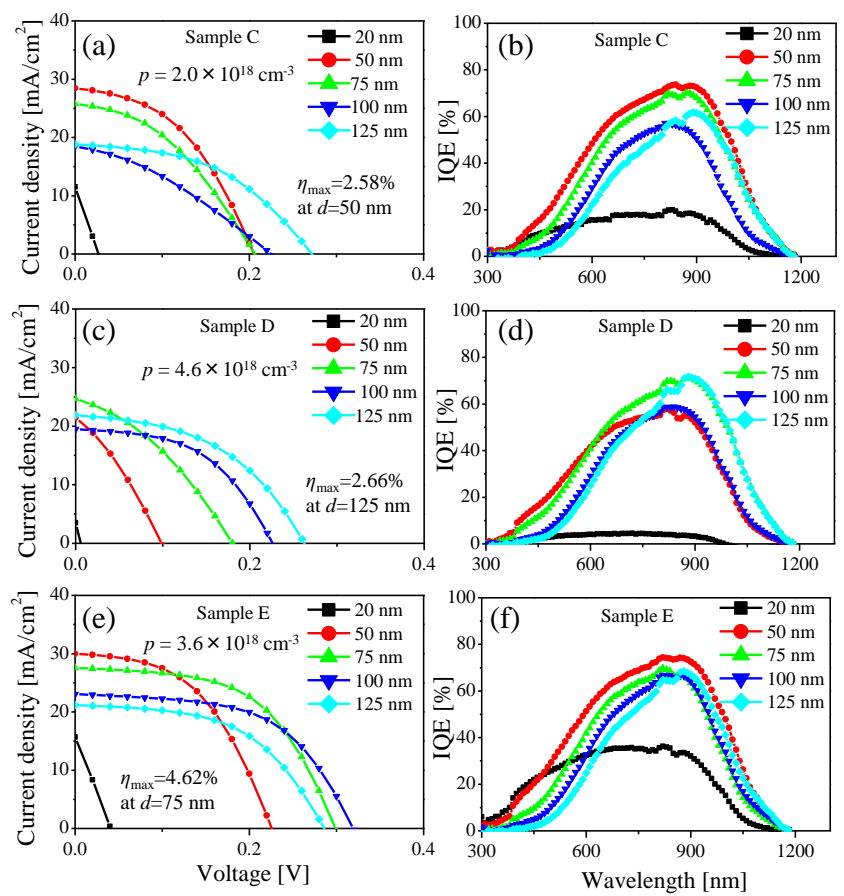

Fig. 8 
Table 1 Solar cell properties of the best solar cell in each sample are specified. For comparison, those of $\mathrm{p}-\mathrm{BaSi}_{2} / \mathrm{n}-\mathrm{Si}$ solar cells on a flat $\mathrm{Si}(111)$ [14] are shown.

\begin{tabular}{|c|c|c|c|c|c|c|c|c|c|}
\hline \multirow[b]{2}{*}{ Sample } & $d$ & $J_{\mathrm{SC}}$ & $V_{\mathrm{OC}}$ & $F F$ & $\eta$ & $R_{\mathrm{S}}$ & $R_{\mathrm{SH}}$ & \multirow[b]{2}{*}{$\gamma$} & $J_{0}$ \\
\hline & {$[\mathrm{nm}]$} & {$\left[\mathrm{mA} / \mathrm{cm}^{2}\right]$} & {$[\mathrm{V}]$} & {$[\%]$} & {$[\%]$} & {$[\Omega]$} & {$[\Omega]$} & & {$\left[\mathrm{mA} / \mathrm{cm}^{2}\right]$} \\
\hline $\mathrm{C}$ & 50 & 28.5 & 0.20 & 44.3 & 2.58 & 209 & 30476 & 1.16 & $2.42 \times 10^{-4}$ \\
\hline $\mathrm{D}$ & 125 & 21.8 & 0.26 & 46.4 & 2.66 & 256 & 43182 & 2.65 & $3.15 \times 10^{-3}$ \\
\hline $\mathrm{E}$ & 75 & 27.6 & 0.30 & 54.9 & 4.62 & 208 & 61839 & 1.23 & $1.68 \times 10^{-5}$ \\
\hline \multicolumn{10}{|l|}{ Reference } \\
\hline & 20 & 35.2 & 0.47 & 60.0 & 9.9 & 128 & 10046 & 1.17 & $1.49 \times 10^{-5}$ \\
\hline [14] & & & & & & & & & \\
\hline
\end{tabular}

